\title{
Efficacy of proprioceptive training on the recovery of total joint arthroplasty patients: a meta-analysis
}

\author{
Wen-chao Zhang and Deng Xiao*
}

\begin{abstract}
Background: Optimal balance control is of paramount importance for function recovery after total joint arthroplasty (TJA). The study objective of this meta-analysis was to assess the short- and mid-term effects of proprioceptive and balance training for patients undergoing TJA.

Methods: Electronic searches were conducted from PubMed, Cochrane library, and Embase databases to identify eligible RCTs through May 2020. Standard mean difference (SMD) with 95\% confidence interval (95\%Cl) was applied to calculate pooled effect estimates between proprioceptive and balance training and control group. Main outcomes were self-reported functionality, balance, pain, quality of life, and function (range of motion).

Results: Seven randomized controlled trials were finally included in this meta-analysis. Pooled results found that balance and proprioceptive trainings have a positive role in improving self-reported functionality at short-term after TJA. Moreover, balance and proprioceptive trainings were associated with an increase of the balance at short- and mid-term after TJA. These results were further confirmed by subgroup analysis between preoperative and postoperative administration of balance and proprioceptive trainings.

Conclusion: Our meta-analysis suggests that balance and proprioceptive trainings after TJA improved self-reported functionality and balance. These improvements were maintained at mid-terms. More research is needed to confirm balance and proprioceptive trainings for pain and quality of life for TJA.
\end{abstract}

Keywords: Osteoarthritis, Proprioceptive training, Meta-analysis

\section{Background}

Osteoarthritis (OA) is the most prevalent joint disease characterized by joint pain, tenderness, and stiffness that finally can lead to the loss of joint function [1-3]. Joint arthroplasty is offered when conservative therapy does not alleviate severe pain or dysfunction of the joint [4]. Hip and knee arthroplasty costs exceeded US $\$ 1087.43$ million [5]. These numbers are expected to rise further

\footnotetext{
*Correspondence: lim5345@163.com

Department of Neurorehabilitation, The Affiliated Rehabilitation Hospital of Chongqing Medical University, No. 50, Wenhuaqicun, Chongqing, Jiulongpo district, China
}

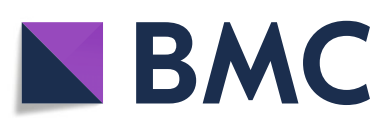

(c) The Author(s). 2020 Open Access This article is licensed under a Creative Commons Attribution 4.0 International License, which permits use, sharing, adaptation, distribution and reproduction in any medium or format, as long as you give appropriate credit to the original author(s) and the source, provide a link to the Creative Commons licence, and indicate if changes were made. The images or other third party material in this article are included in the article's Creative Commons licence, unless indicated otherwise in a credit line to the material. If material is not included in the article's Creative Commons licence and your intended use is not permitted by statutory regulation or exceeds the permitted use, you will need to obtain permission directly from the copyright holder. To view a copy of this licence, visit http://creativecommons.org/licenses/by/4.0/. The Creative Commons Public Domain Dedication waiver (http://creativecommons.org/publicdomain/zero/1.0/) applies to the data made available in this article, unless otherwise stated in a credit line to the data. due to increasing proportion of aging population and obese population [6].

The results of joint arthroplasty procedures are overall satisfactory [7]. However, there are some barriers for balance and postoperative function $[8,9]$. One study that investigated postoperative function in patients after total knee arthroplasty (TKA) indicated that postoperative pain and lack of effectiveness exercise are key causes of prolonged recovery following joint arthroplasty [10]. Among these adversities are exposure to deficits in the proprioceptive system, and thus, it is difficult to main postural control [11]. 
To optimize joint arthroplasty, it is necessary to explore additional effective rehabilitation protocols. Proprioceptive training has been investigated as a mean to achieve complete rehabilitation. Studies examining proprioceptive training following joint arthroplasty have produced conflicting results. Jogi et al. [12] revealed that proprioceptive training protocol resulted in significantly greater improvements in function than that of typical exercises alone. However, disagreements still remain about that proprioceptive training did not have any benefits for joint arthroplasty patients [13].

Therefore, this review and meta-analysis systematically assessed the effect of proprioceptive training in patients undergoing total joint arthroplasty (TJA), in terms of post-operative self-reported functionality, balance, pain, quality of life, and postoperative function (range of motion).

\section{Methods}

This meta-analysis was carried out in accordance with the recommendations of the Cochrane Collaboration and the Preferred Reporting Items for Systematic Reviews and Meta-Analyses (PRISMA) guidelines [14].

\section{Search strategy}

Three electronic databases (PubMed, Cochrane library, and Embase databases) were used for article retrieval. Two reviewers independently searched these databases from inception to May 20, 2020. The search criteria "proprioceptive training", "balance exercise", "education", "training", "total knee arthroplasty/replacement", "TKA", "TKR", "total hip arthroplasty/replacement", "THA", and "THR" were used in keywords for search. No restrictions were applied for the country, year of publication, publication status, type of study, or language. And the reference lists were also manually reviewed to find relevant studies that were not found during the database searches.

\section{Inclusion criteria}

Inclusion criteria were based on the PICOS strategy: (P) adult patients with knee or hip joint degenerative disease and received TKA or THA; (I) intervention group was proprioceptive training; (C) comparison group was standard procedure or no intervention; $(\mathrm{O})$ outcomes including self-reported functionality (SRF), quality of life (QoL), Biodex Balance System (BBS), pain (P), balance

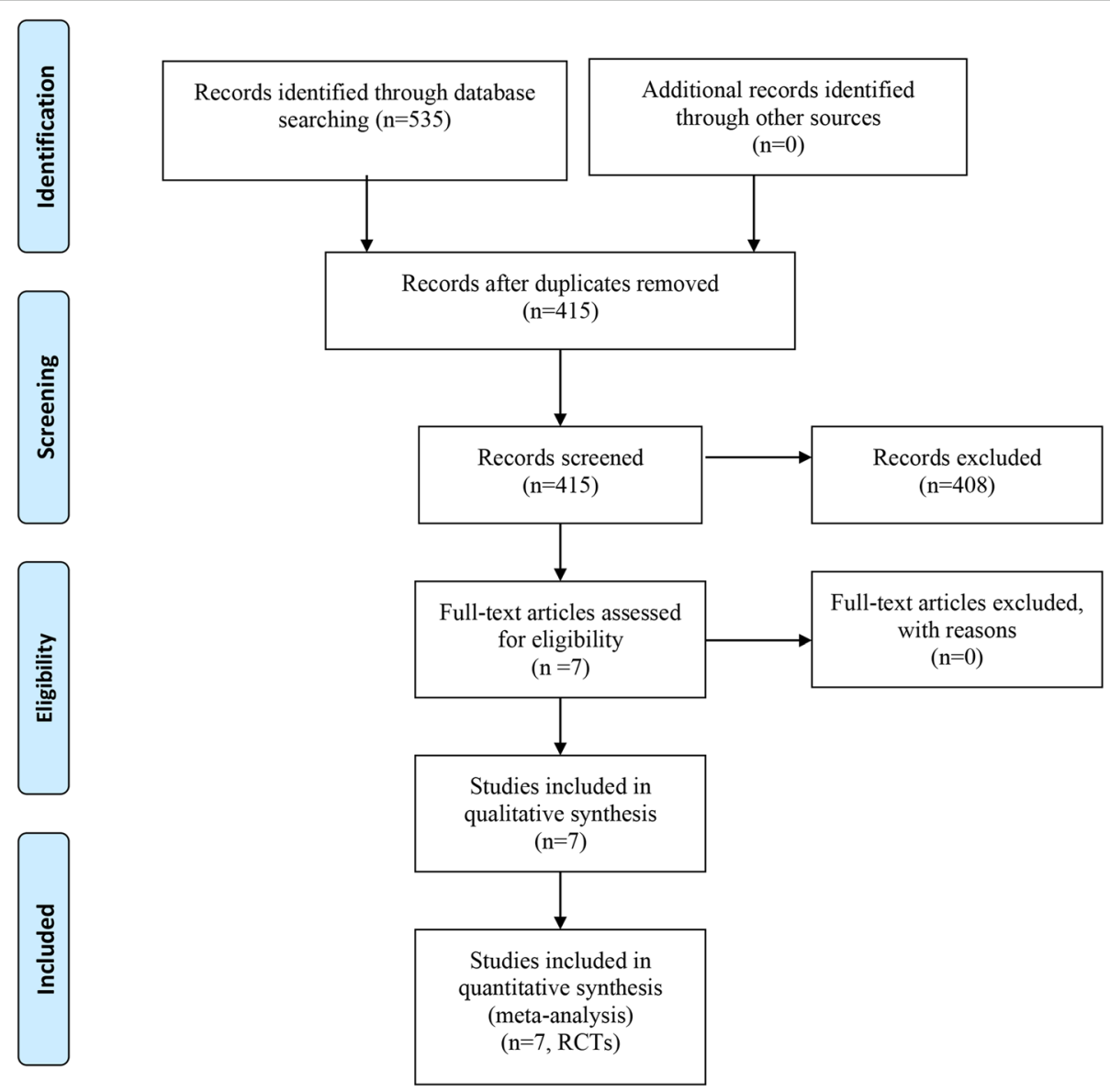

Fig. 1 The PRISMA flowchart regarding the study selection process 


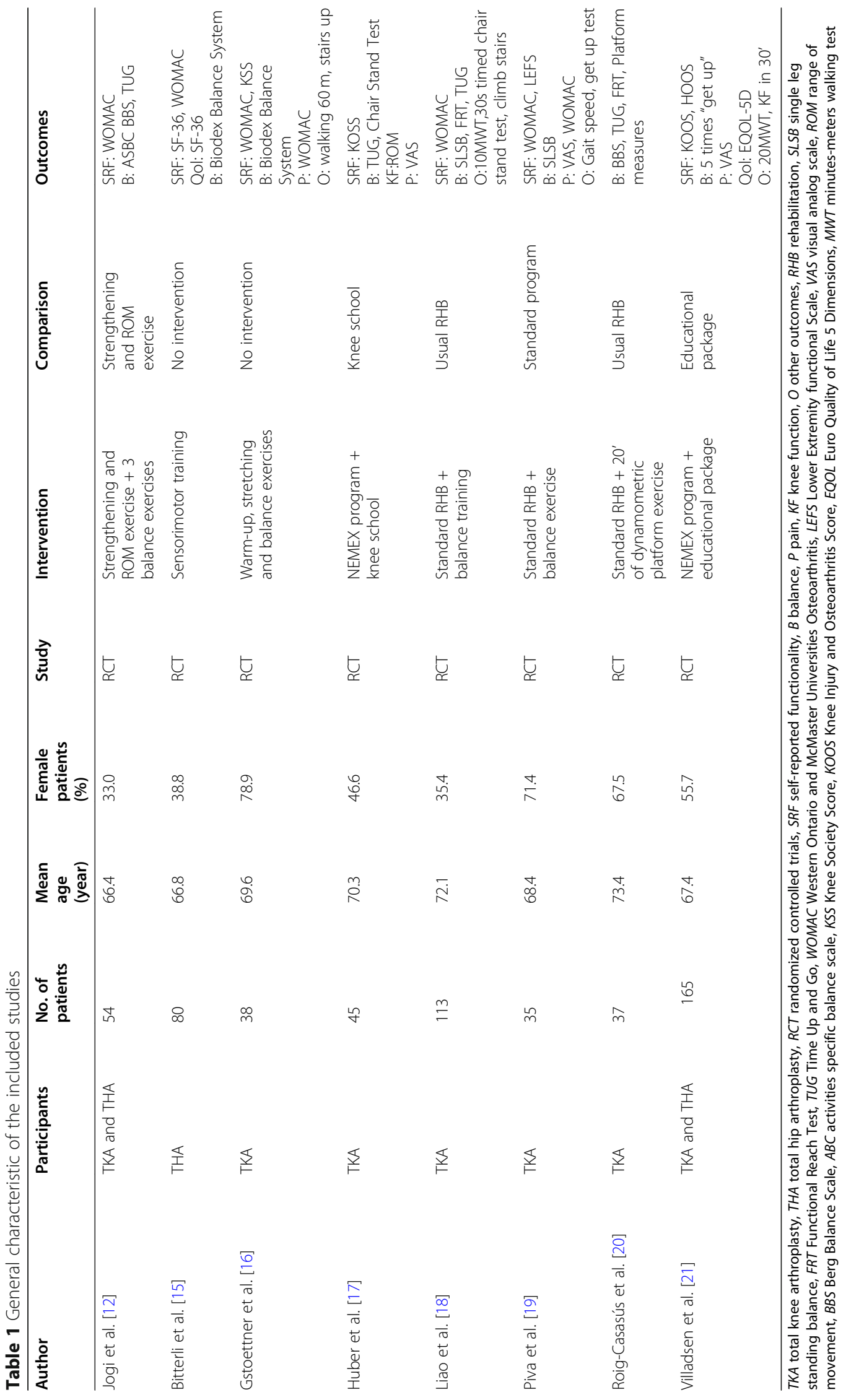




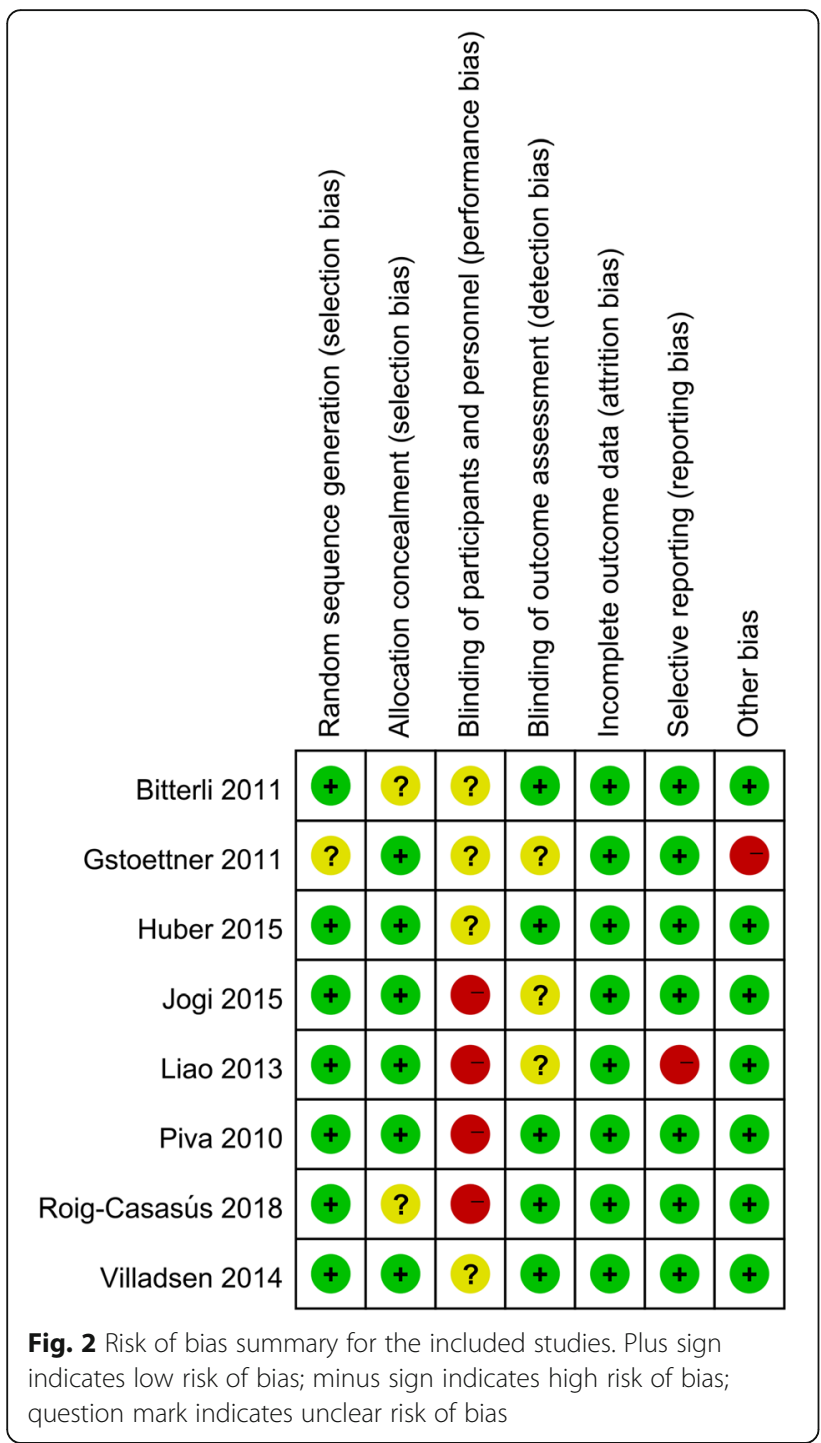

question mark indicates unclear risk of bias
(B), and knee function (KF); (S) randomized controlled trials (RCTs).

Exclusion criteria for this meta-analysis were as follows: (1) studies without available data; (2) abstract of full text was not available; (3) non-RCTs; (4) review manuscripts; (5) non-relevant studies.

\section{Data extraction}

General information of the included studies was extracted by using a standardized data extraction form and recorded into Excel (Microsoft Excel 2019, Microsoft, Redmond, WA, USA). Study data extracted included first author, publication year, participants (total knee arthroplasty, total hip arthroplasty, or both), number of patients, mean age of patients, female patients (\%), study type, intervention, comparison, and outcomes. If differences in opinion existed, the diagnosis was decided by their discussion and to reach total agreement.

\section{Risk of bias}

Two reviewers (Wen-chao Zhang and Deng Xiao) independently complete the process of quality assessment. The following aspects will be assessed: random sequence generation (selection bias), allocation concealment (selection bias), blinding of participants and personnel (performance bias), incomplete outcome data (attrition bias), selective reporting (reporting bias), and other bias. Each aspect was classified as "low," "high," or "unclear" according to Cochrane Collaboration Handbook recommendations.

Finally, quality of evidence was generated according to GRADE (Grading of Recommendations Assessment, Development and Evaluation) methodology and performed by utilizing the GRADE Pro GDT software. A total of four categories were used: high, moderate, low, or very low.

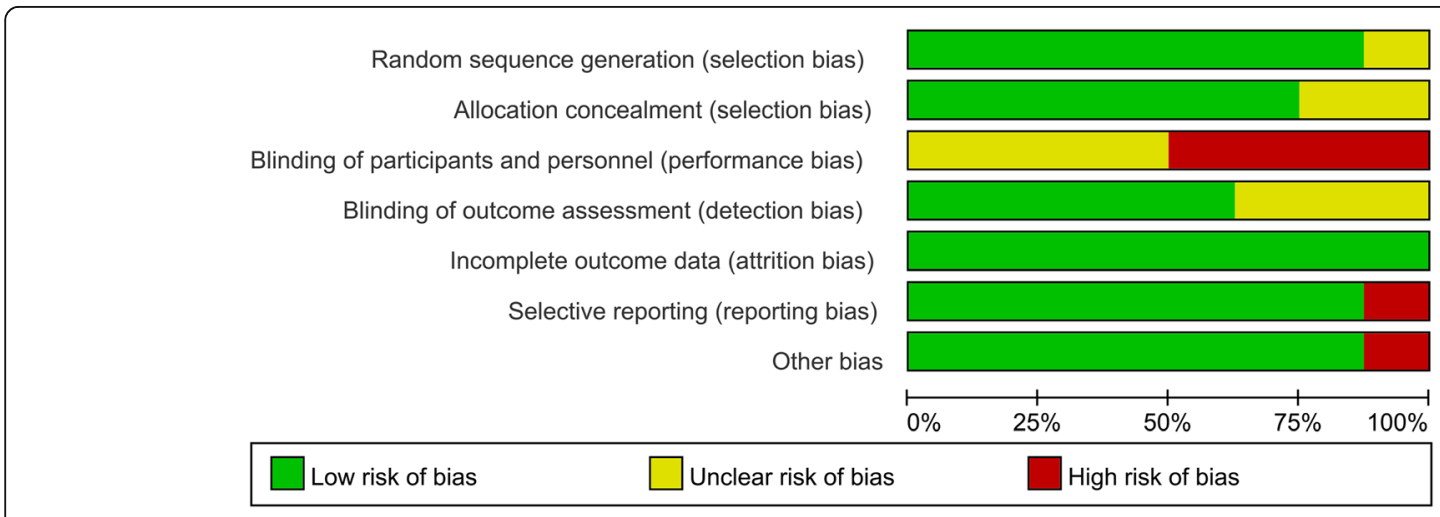

Fig. 3 Risk of bias graph for the included studies 


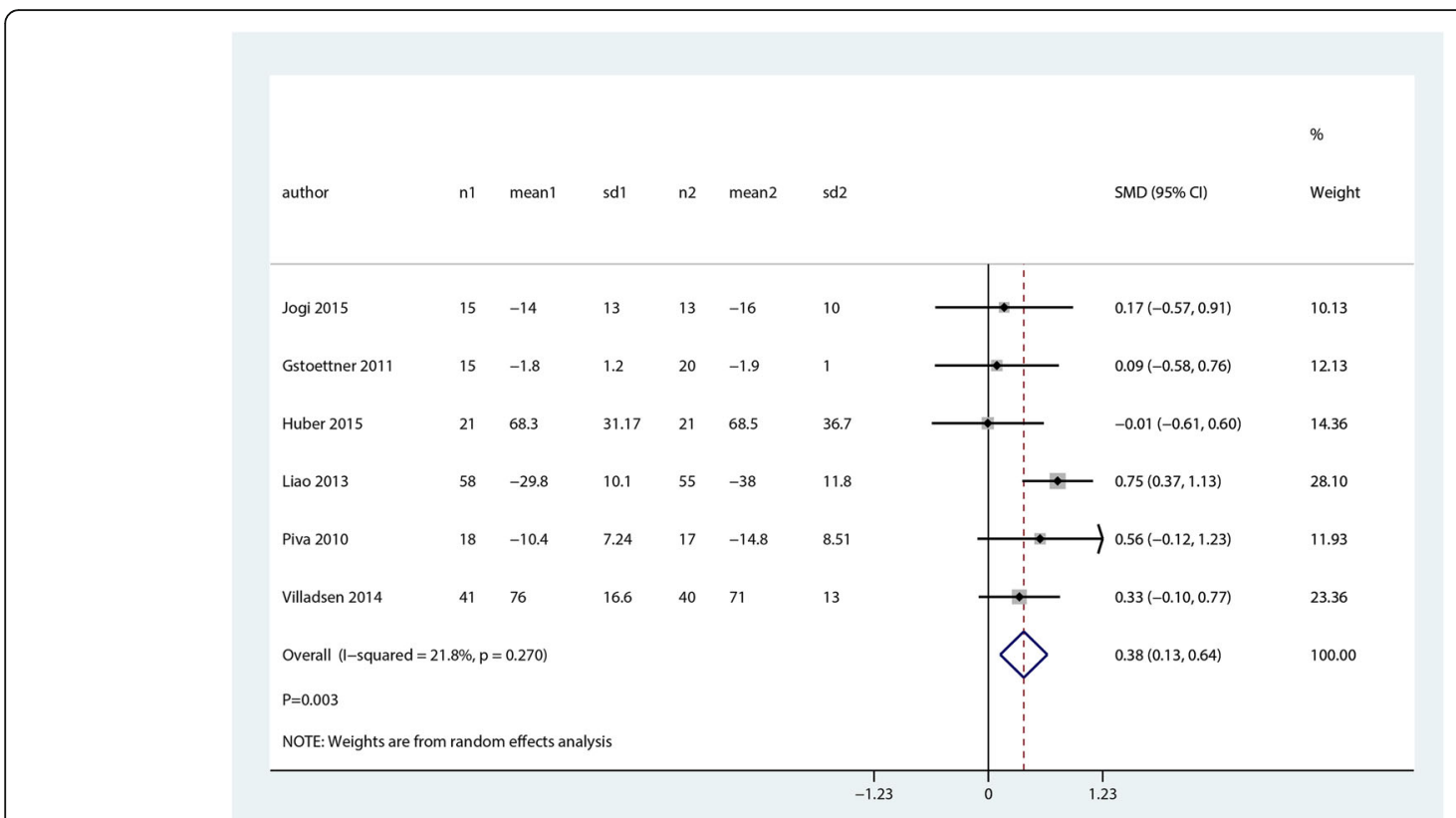

Fig. 4 Balance and proprioceptive trainings and control on self-reported functionality

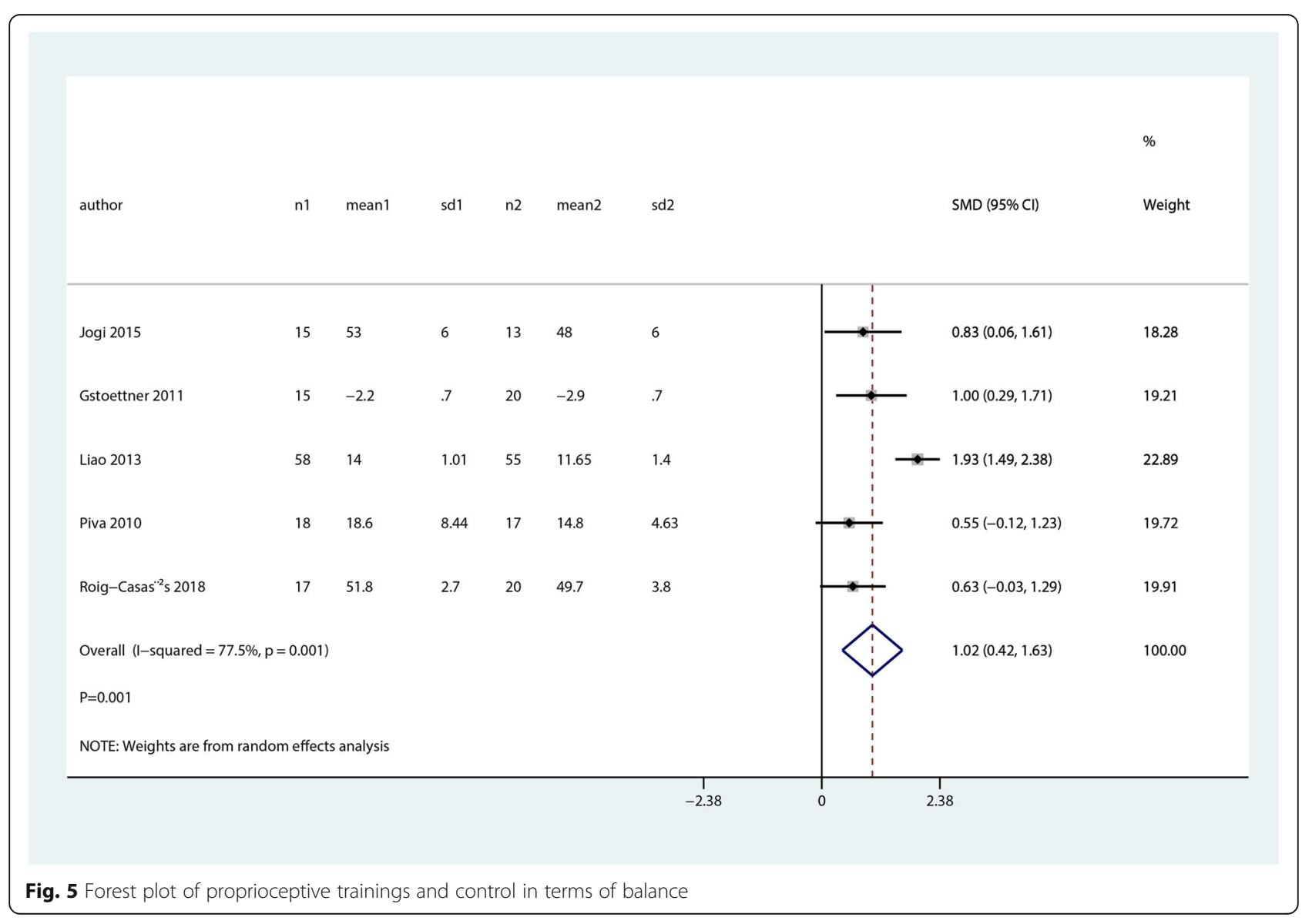




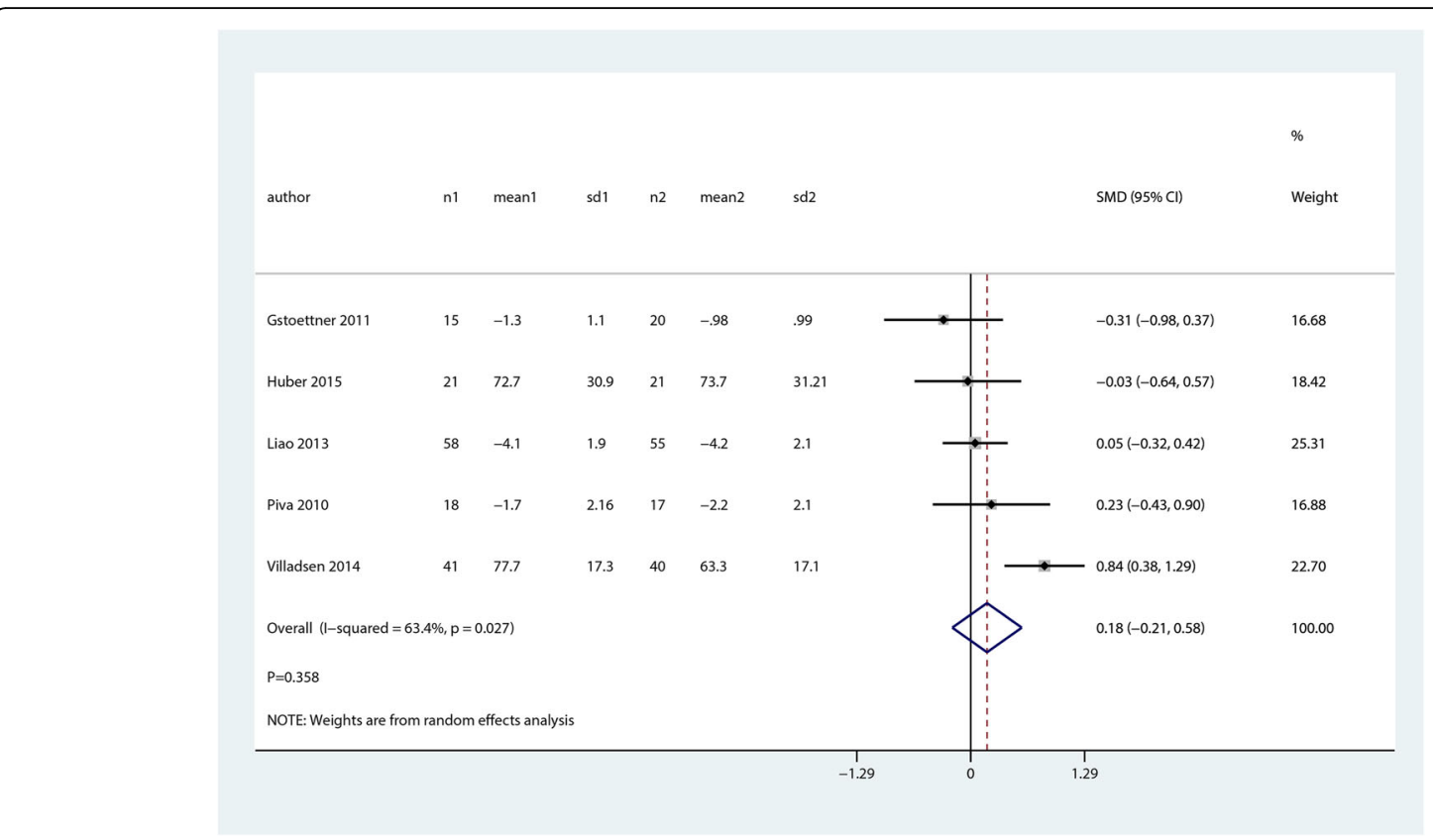

Fig. 6 Forest plot of proprioceptive trainings and control in terms of pain scores

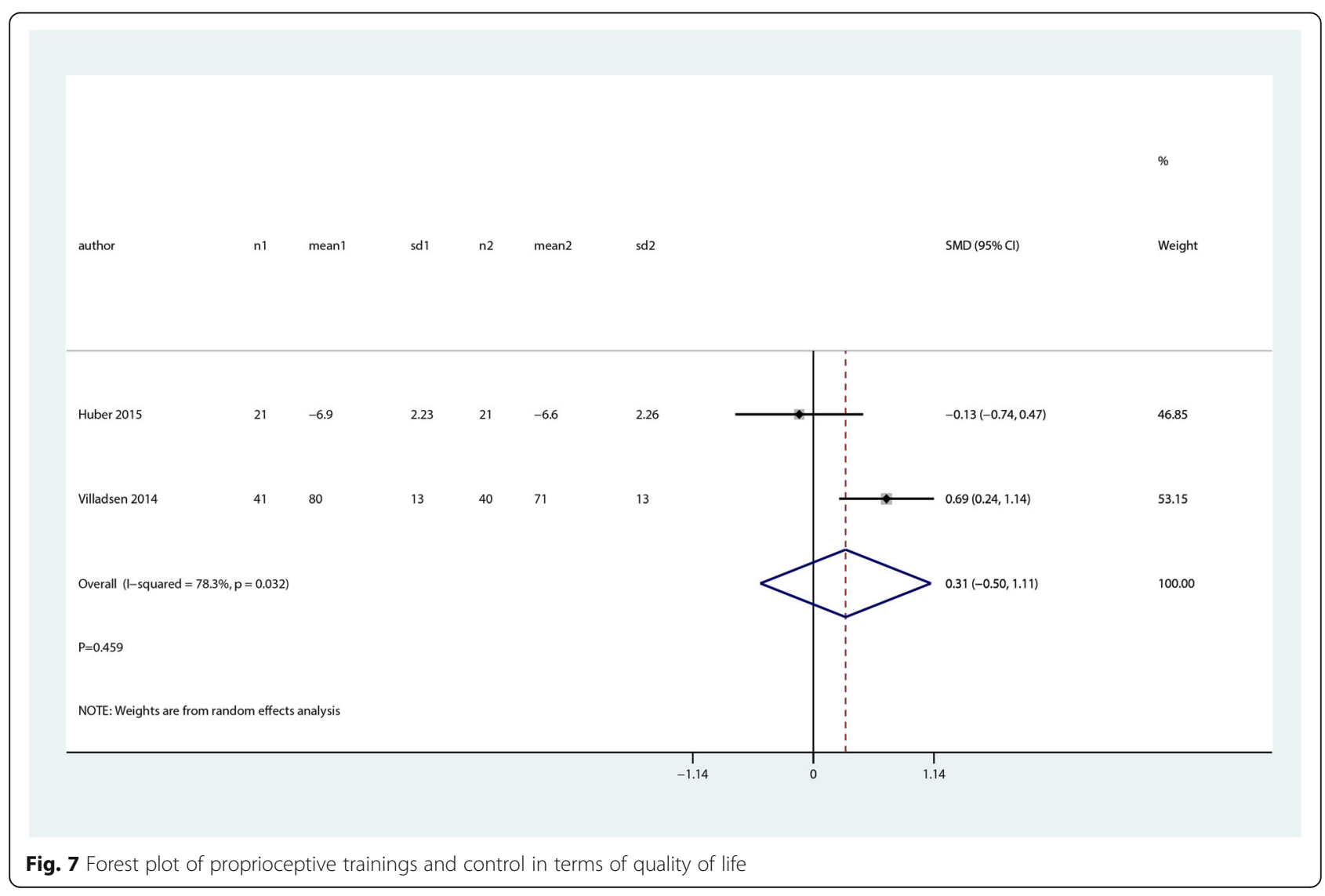




\section{Statistical analysis}

The statistical analysis was performed using the Stata 12.0 software (Stata Corp LLC, College Station, TX, USA). Pooled data were assessed by standard mean difference (SMD) with $95 \%$ confidence intervals (CIs), and $P<0.05$ was considered statistically significant. The $I^{2}$ value was used to assess the degree of heterogeneity $\left(I^{2}\right.$ of $0 \%$ indicated no heterogeneity; $I^{2}>50 \%$, low heterogeneity, and $I^{2} \geq 50 \%$, high heterogeneity). Publication bias was assessed by visual inspection of the funnel plot, and we accepted that a symmetrical funnel plot was likely to indicate low publication bias. A subgroup analysis was performed by duration of follow-up: early period (6-12 weeks), mid-term (6-12 months), and longterm (> 12 months). Another subgroup analysis was conducted by the timing of the intervention: preoperative intervention and postoperative intervention.

\section{Results}

\section{Search results}

The initial literature search retrieved 535 relevant articles. After duplicates were discarded, 415 studies were screened. After reviewing the abstracts, 408 articles were excluded because they did not meet inclusion and exclusion criteria; therefore, leaving 7 studies that matched the selection criteria and were suitable for meta-analysis (Fig. 1) [12, 15-21]. A total of 567 (balance and proprioceptive trainings, 282; control group, 285) patients were enrolled in the studies; the general characteristic of the included patients is summarized in Table 1. These reports were published between 2010 and 2018 for evaluation. The mean size of patient sample was 70 (range from 35 to 165). One study included only total hip arthroplasty patients, 4 included only total knee arthroplasty patients, and 2 included both total hip arthroplasty and total knee arthroplasty patients. Control group interventions mainly consisted of strengthening and range of motion exercise, standard program, knee school, usual RHB, and educational package. The interventions were the same as those in the corresponding control groups, but additionally included an experimental balance training, i.e., warm-up, stretching and balance exercises, NEMEX program + knee school, strengthening and range of motion exercise +3 balance exercises, sensorimotor training, and standard RHB + balance exercise.

\section{Risk of bias}

The risk of bias summary and risk of bias graph for included 7 RCTs are shown in Figs. 2 and 3. In general,

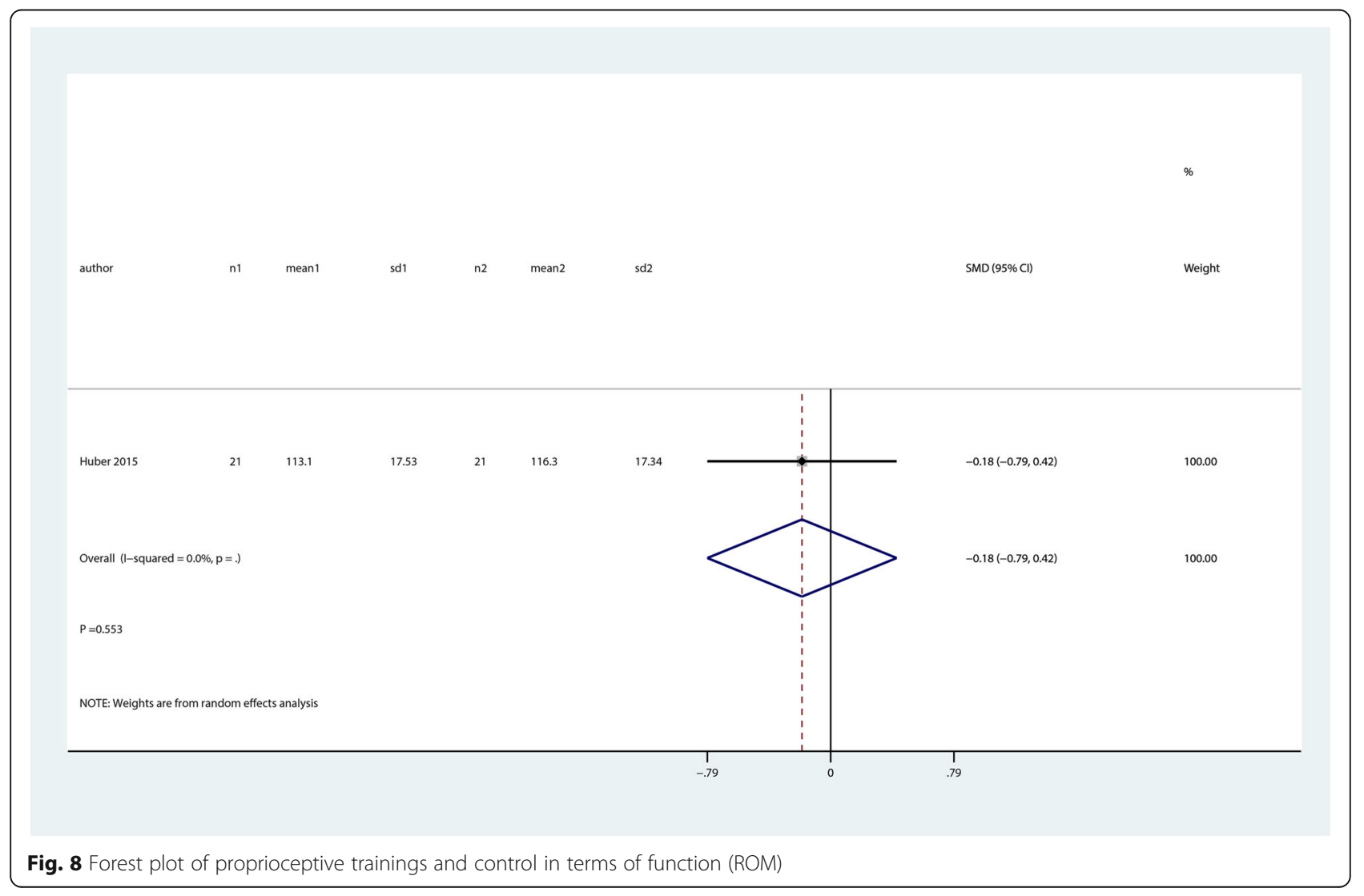


5 studies (Jogi et al. [12], Gstoettner et al. [16], Liao et al. [18], Piva et al. [19], and Roig-Casasús et al. [20]) were considered to have high risk of bias while the other 3 have unclear risk of bias. Seven trials had a low risk of bias in random sequence generation, and six trials had a low risk of bias in allocation concealment. Four studies had a high risk of bias in blinding of participants and personnel. One study had a high risk of bias in selective reporting, and one study had a high risk of bias in other bias.

\section{Results of meta-analysis}

\section{Balance and proprioceptive trainings for functional outcomes at early postoperative}

The breakdown number of studies for the effects between balance and proprioceptive trainings and control groups in patients after TJA on self-reported functionality at early postoperative (SMD $0.38 ; 95 \%$ CI 0.13 to 0.64; $P=0.003$, Fig. 4).

We noted that balance and proprioceptive trainings were associated with higher balance at early postoperative (SMD 1.02; 95\% CI 0.42 to $1.63 ; P=0.001$, Fig. 5) as compared with control group, while no significant differences between groups for pain scores (SMD 0.18; $95 \%$ CI -0.21 to $0.58 ; P=0.358$, Fig. 6).

There were no significant differences between balance and proprioceptive trainings and control groups for quality of life (SMD 0.31; 95\% CI -0.50 to $1.11 ; P=$ 0.459 , Fig. 7) and function (ROM, SMD - 0.18; $95 \% \mathrm{CI}$ -0.79 to $0.42 ; P=0.553$, Fig. 8 ).

\section{Balance and proprioceptive trainings for functional outcomes at mid-term}

Data for the effect of balance and proprioceptive trainings versus control groups on the self-reported functionality at mid-term were available in 4 studies. There was no significant difference between balance and proprioceptive trainings and control groups in terms of the selfreported functionality at mid-term (SMD 0.67; 95\% CI 0.04 to $1.38 ; P=0.066$, Fig. 9).

We noted that balance and proprioceptive trainings are associated with higher balance at mid-term as compared with control group (SMD 0.75; 95\% CI 0.41 to $1.08 ; P=0.000$, Fig. 10). There was no significant difference between balance and proprioceptive trainings and control groups in terms of the pain (SMD 0.56; 95\% CI -0.25 to $1.36 ; P=0.177$, Fig. 11 ) and quality of life

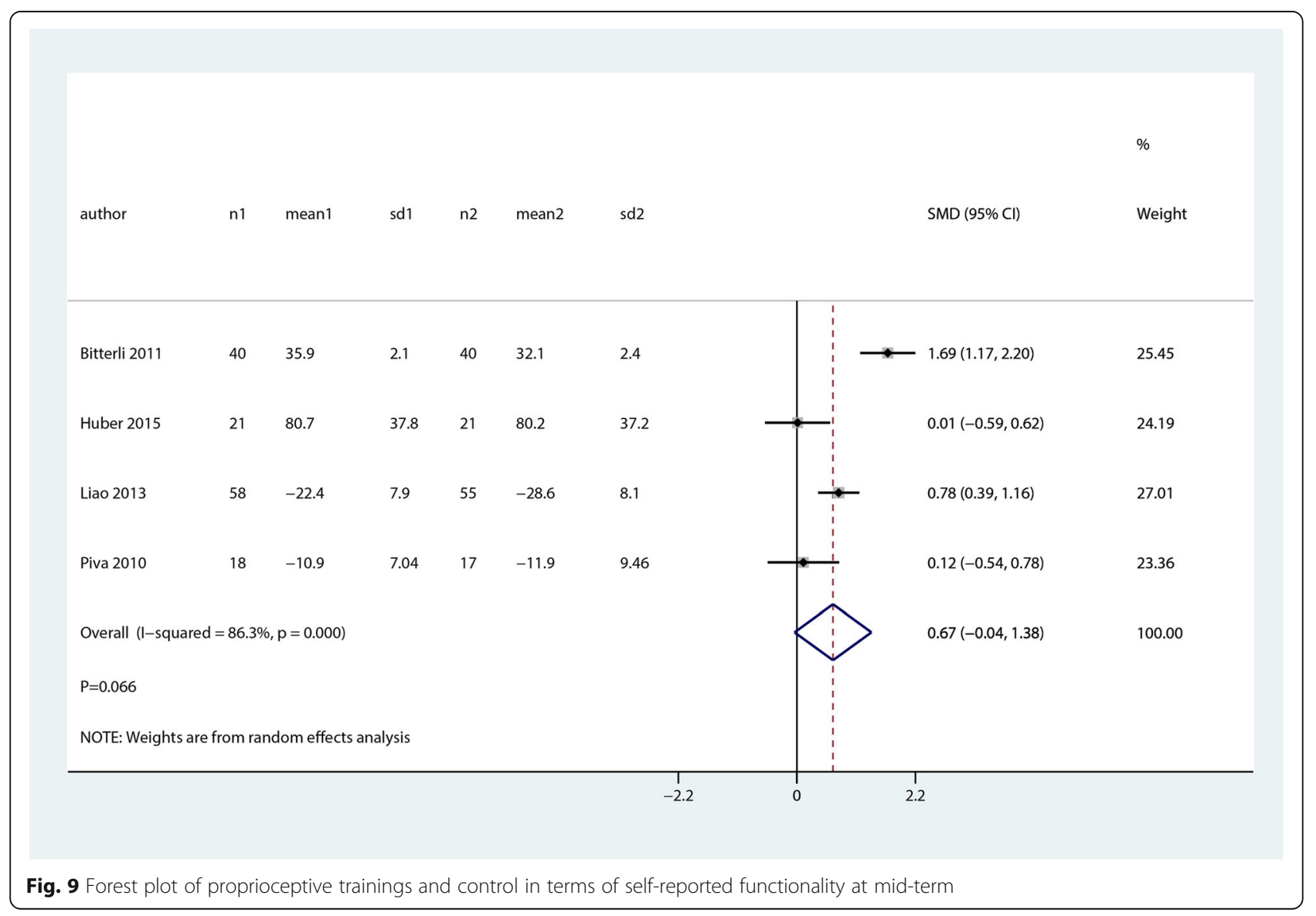




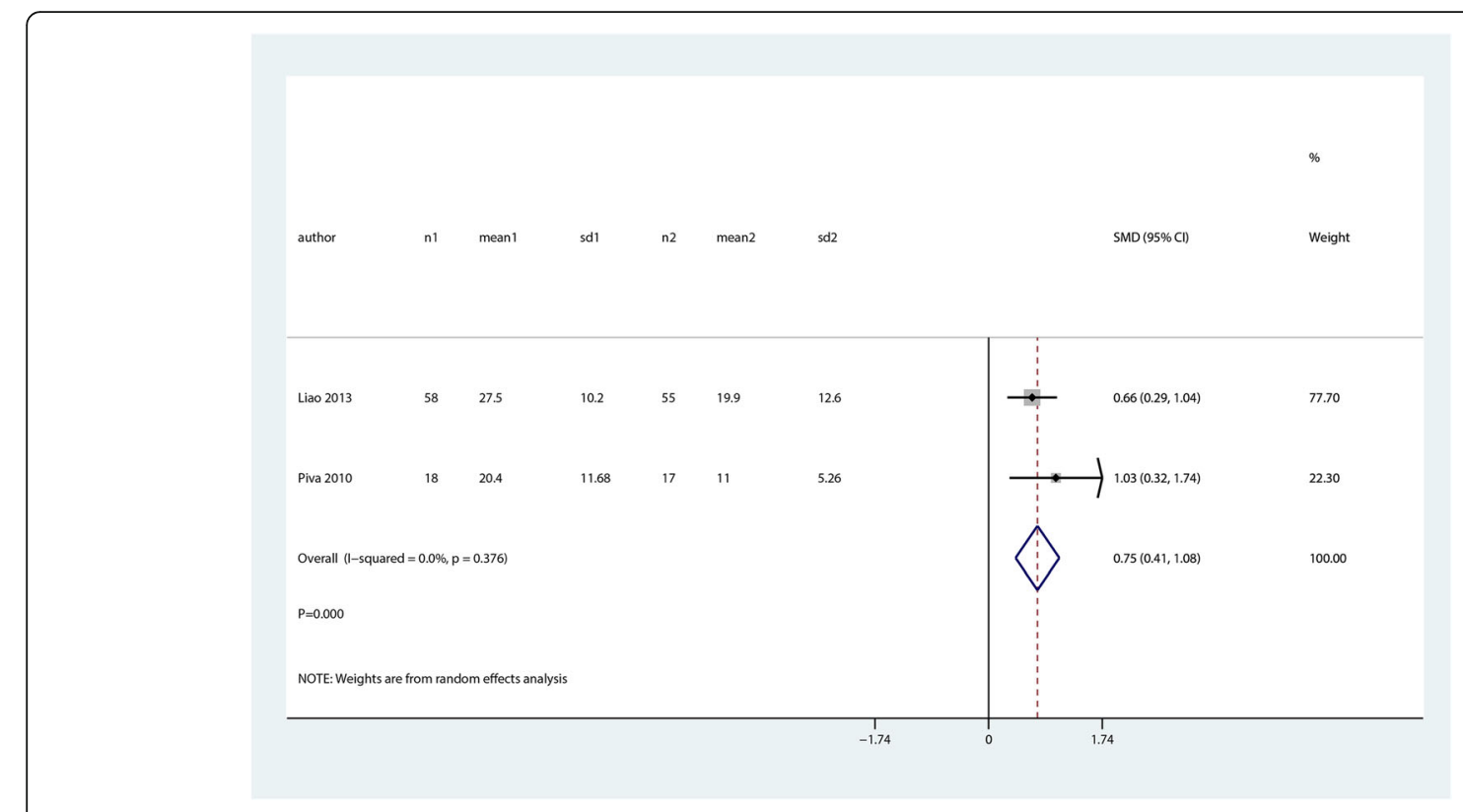

Fig. 10 Forest plot of proprioceptive trainings and control in terms of balance at mid-term

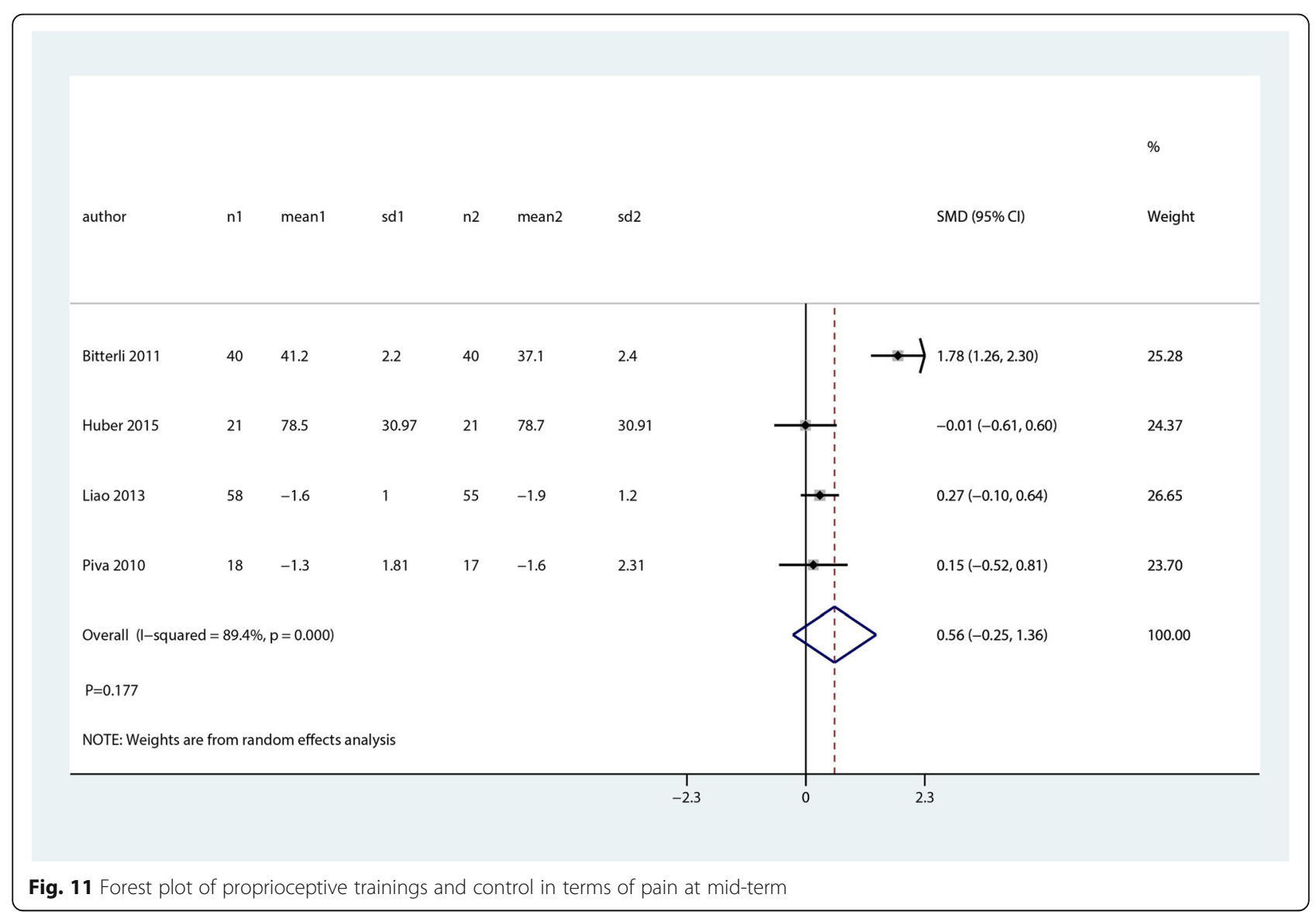


(SMD 1.40; $95 \% \mathrm{CI}-1.48$ to $4.27 ; P=0.342$, Fig. 12 ) at mid-term.

\section{Subgroup analysis}

Results of the subgroup analysis are presented in Table 2. The findings of pain, ROM, QoL, and balance were consistent in all subgroup analyses except for the self-reported functionality. In an analysis stratified by timing of training (preoperative vs postoperative), the summary SMD from postoperative interventions (SMD 0.61; $95 \%$ CI 0.31-0.92, $P=0.000$ ) showed that there was statistically significance between balance and proprioceptive trainings and controls, but no significant difference in preoperative intervention (OR 0.19; 95\% CI - 0.12-0.50, $P=0.236$ ).

\section{Grade profile evidence and publication bias}

The GRADE working group grade level of evidence is low for ROM and QoL and moderate for pain, selfreported functionality, and balance (Table 3). Publication bias was assessed by visual inspection of the funnel plots, and no distinct asymmetry was found (Fig. 13).

\section{Discussion}

This meta-analysis appraised the effects of balance and proprioceptive trainings in patients undergoing TJA. Based on the pooled effects, balance and proprioceptive trainings enhanced the early postoperative functional outcomes after TJA. What's more, follow-up evaluations confirmed that the promotion effects of balance and proprioceptive trainings for balance were maintained at mid-term. In subgroup analysis, postoperative balance and proprioceptive trainings were associated with better functional outcomes in TJA patients.

A major strength of this meta-analysis is that we assessed the most important clinical outcome, selfreported functionality, and balance at early period and mid-term follow-up. Another strength of this metaanalysis was the good stability of the results, which is reflected in subgroup analysis.

Previous study has reported that proprioceptive inaccuracy is the main cause of functional deterioration. According to the theory mentioned above, well-targeted post-operative proprioceptive intervention can further enhance the patients' functional performance and quality of life. An observational study has pointed out that game-based balance exercises could improve motor performance and postural control in long-term follow-up [22]. Kakavas et al. [23] reported that training can improve function and finally to optimize return to play in anterior cruciate ligament. These results suggest that proprioceptive intervention can also be administrated in TJA patients to improve postoperative function.

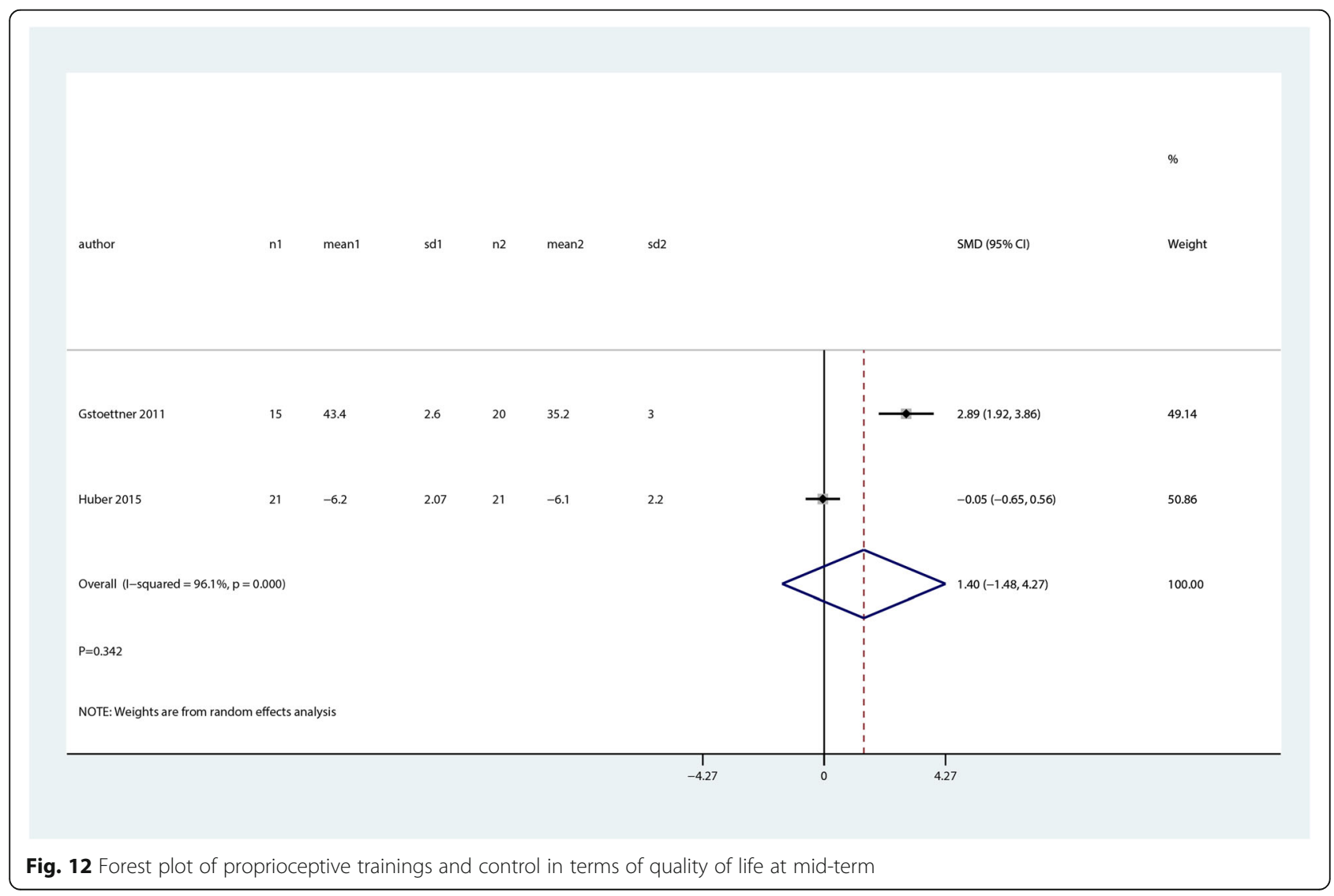


Table 2 Subgroup analysis for the outcomes

\begin{tabular}{|c|c|c|c|c|c|c|c|c|}
\hline \multirow[t]{2}{*}{ Subgroup } & \multicolumn{4}{|c|}{ Early post-operative effects } & \multicolumn{4}{|c|}{ Mid-term effects } \\
\hline & Trials & Sample & SMD (95\% Cl) & $P$ value & Trials & Sample & SMD (95\% Cl) & $P$ value \\
\hline \multicolumn{9}{|l|}{ Preoperative interventions } \\
\hline Pain & 3 & 158 & $0.20(-0.53,0.92)$ & 0.593 & 2 & 122 & $0.89(-0.86,2.65)$ & 0.317 \\
\hline ROM & 1 & 42 & $-0.18(-0.79,0.42)$ & 0.553 & & & & \\
\hline QoL & 2 & 123 & $0.31(-0.50,1.11)$ & 0.459 & 2 & 77 & $1.40(-1.48,4.27)$ & 0.342 \\
\hline Self-reported functionality & 3 & 158 & $0.19(-0.12,0.50)$ & 0.236 & 2 & 122 & $0.86(-0.78,2.50)$ & 0.305 \\
\hline Balance & 1 & 35 & $1.00(0.29,1.71)$ & 0.006 & & & & \\
\hline \multicolumn{9}{|l|}{ Postoperative interventions } \\
\hline Pain & 2 & 148 & $0.09(-0.23,0.41)$ & 0.575 & 2 & 148 & $0.24(-0.08,0.57)$ & 0.143 \\
\hline \multicolumn{9}{|l|}{$\mathrm{ROM}$} \\
\hline \multicolumn{9}{|l|}{ QoL } \\
\hline Self-reported functionality & 3 & 176 & $0.61(0.31,0.92)$ & 0.000 & 2 & 148 & $0.51(-0.13,1.14)$ & 0.116 \\
\hline Balance & 4 & 213 & $1.02(0.26,1.77)$ & 0.008 & 2 & 148 & $0.75(0.41,1.08)$ & 0.000 \\
\hline \multicolumn{9}{|l|}{ Overall effects } \\
\hline Pain & 5 & 306 & $0.18(-0.21,0.58)$ & 0.358 & 4 & 270 & $0.56(-0.25,1.36)$ & 0.177 \\
\hline ROM & 1 & 42 & $-0.18(-0.79,0.42)$ & 0.553 & & & & \\
\hline QoL & 2 & 123 & $0.31(-0.50,1.11)$ & 0.459 & 2 & 78 & $1.40(-1.48,4.27)$ & 0.342 \\
\hline Self-reported functionality & 6 & 334 & $0.38(0.13,0.64)$ & 0.003 & 4 & 270 & $0.67(-0.04,1.38)$ & 0.066 \\
\hline Balance & 5 & 248 & $1.02(0.42,1.63)$ & 0.001 & 2 & 148 & $0.75(0.41,1.08)$ & 0.000 \\
\hline
\end{tabular}

Another important finding from our analysis is that balance and proprioceptive trainings showed no benefit for pain, range of motion, and quality of life at early period and mid-term follow-up. Appropriately 30\% of patients experience moderate to severe pain at 1 year after surgery [24]. Several mechanisms may underlie postoperative pain, including peripheral and central sensitization. Pain management is a critical but complex issue in the relief of acute pain, particularly important for functionally recovery for TJA patients. Kosek et al. [25] reported that exercise has no effects on the pain severity in osteoarthritis patients. These results are similar to our results and agree that the balance training has no effects on pain control in TJA patients.

Consistent with pain outcome, balance and proprioceptive trainings also have no effects on the quality of life after TJA compared with standard procedures. TJA itself could significantly improve the quality of life in TJA patients. There was no further improvement in balance and proprioceptive trainings than that of standard procedures. Due to the low number of these studies, more studies are needed to confirm and elucidate this finding. These results were clinically important as balance and proprioceptive trainings only have benefit for improving balance and self-reported functionality. These improvement effects were maintained at midterm follow-up. Moreover, postoperative balance and proprioceptive trainings was superior than preoperative balance and proprioceptive trainings in terms of the balance and self-reported functionality. One important consideration was that TJA surgeries have vital influence on the proprioception. Thus, postoperative balance and proprioceptive trainings could improve the balance and functionality at some extent. Lee et al. [26] included a total of 8 RCTs and assessed the balance training after hip fracture. Results suggested that balance training significantly improve overall physical functioning and balance. And author also recommended that balance

Table 3 Grade evidence of the outcomes

\begin{tabular}{llll}
\hline Outcomes & Relative effect $\mathbf{( 9 5 \% ~ C l )}$ & No. of participants (studies) & Certainty of the evidence (GRADE) \\
\hline Pain & $0.18(-0.21,0.58)$ & $306(5)$ & Moderate \\
ROM & $-0.18(-0.79,0.42)$ & $42(1)$ & Low \\
QoL & $0.31(-0.50,1.11)$ & $123(2)$ & Low \\
Self-reported functionality & $0.38(0.13,0.64)$ & $334(6)$ & Moderate \\
Balance & $1.02(0.42,1.63)$ & $248(5)$ & Moderate \\
\hline
\end{tabular}




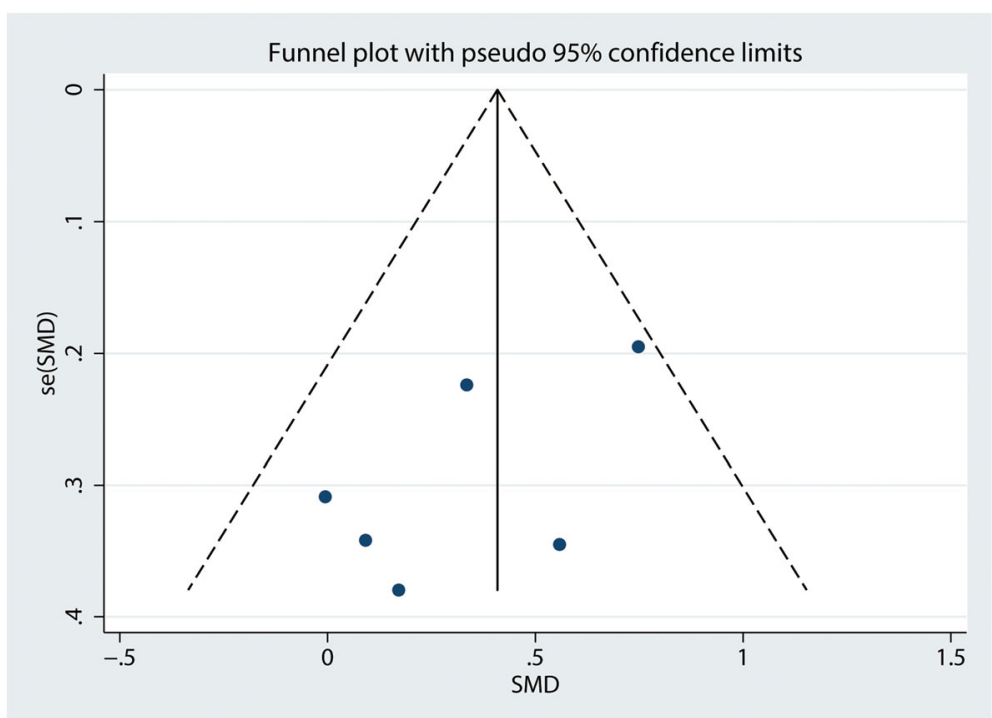

Fig. 13 Funnel plot of self-reported functionality

training should be specifically included in postoperative rehabilitation programs.

To prevent selection bias within this meta-analysis, only RCTs were included for final analysis. However, some potential limitations in this study were inevitable. Firstly, the duration, timing, and type of the balance and proprioceptive trainings differed across studies. This may affect the final results; in addition, some important data (long-term functional outcomes) were lacking, hampering analysis. Secondly, small sample size of the included studies may render the results underpowered. Thirdly, the heterogeneous outcomes were also a limitation. Subgroup analysis was performed to assess the robustness of results; however, not all planned subgroup analyses could be performed, due to insufficient data reporting. Thus, the heterogeneity could not always be explained. Fourth, the data for pain and other adverse effects was limited, and these results need for more studies to validate. Lastly, the clinical relevance of self-reported functionality and balance remain challenging due the short-term follow-up duration.

\section{Conclusion}

Our meta-analysis suggests that balance and proprioceptive trainings after TJA improved self-reported functionality and balance. These improvements were maintained at midterms and postoperative balance and proprioceptive trainings. However, balance and proprioceptive trainings have no effects on pain relieving, functional recovery, and quality of life after TJA. Considering these effects of balance and proprioceptive trainings, more studies are needed to identify the balance and proprioceptive trainings for pain control and functional outcomes.

\section{Abbreviations}

SMD: Standard mean difference; OA: Osteoarthritis; SRF: Self-reported functionality; QoL: Quality of life; BBS: Biodex Balance System; P: Pain; B: Balance; KF: Knee function; RCTs: Randomized controlled trials; GRADE: Grading of Recommendations Assessment, Development and Evaluation; Cls: Confidence intervals

\section{Acknowledgements \\ Not applicable.}

\section{Authors' contributions}

Wen-chao Zhang and Deng Xiao performed the experiments. Wen-chao Zhang and Deng Xiao supervised the data collection. Wen-chao Zhang and Deng Xiao wrote the initial draft. All the listed authors read and approved the manuscript.

\section{Funding}

Not applicable.

\section{Availability of data and materials}

We declare that the materials described in the manuscript will be free access to all of the reader in the included studies.

Ethics approval and consent to participate

Not applicable.

Consent for publication

Not applicable.

\section{Competing interests}

All the authors in this manuscript have read and approved the final version submitted, and there are no conflicts involved in this submission.

Received: 20 June 2020 Accepted: 23 September 2020

Published online: 03 November 2020

\section{References}

1. Liu Y, Chen X, Zhang P, et al. Comparing total hip arthroplasty and hemiarthroplasty for the treatment of displaced femoral neck fracture in the active elderly over 75 years old: a systematic review and meta-analysis of randomized control trials. J Orthop Surg Res. 2020;15:215. https://doi.org/10. 1186/s13018-020-01725-3. 
2. Peng L, Zeng Y, Wu Y, et al. Clinical, functional and radiographic outcomes o primary total hip arthroplasty between direct anterior approach and posterior approach: a systematic review and meta-analysis. BMC Musculoskelet Disord. 2020;21:338. https://doi.org/10.1186/s12891-020-03318-x.

3. Zhao Z, Ma JX, Ma XL. Different intra-articular injections as therapy for hip osteoarthritis: a systematic review and network meta-analysis. Arthroscopy, 2020, 36: 1452-1464.e1452 DOI: 10.1016/j.arthro.2019.09.043.

4. Wainwright TW, Gill M, McDonald DA, et al. Consensus statement for perioperative care in total hip replacement and total knee replacement surgery: Enhanced Recovery After Surgery (ERAS( $\left.\left(^{(}\right)\right)$society recommendations. Acta Orthop. 2020;91:3-19. https://doi.org/10.1080/ 17453674.2019.1683790.

5. Mazzei CJ, Yurek JW, Patel JN, et al. Providing patient mobilization with a mobility technician improves staff efficiency and constrains cost in primary total hip arthroplasty. J Arthroplasty. 2020. https://doi.org/10.1016/j.arth. 2020.03.042

6. Schwartz AM, Farley KX, Guild GN, et al. Projections and epidemiology of revision hip and knee arthroplasty in the United States to 2030. J Arthroplasty. 2020:35:S79-s85. https://doi.org/10.1016/j.arth.2020.02.030.

7. Koyuncu S, Friis CP, Laigaard J, et al. A systematic review of pain outcomes reported by randomised trials of hip and knee arthroplasty. Anaesthesia. 2020. https://doi.org/10.1111/anae.15118.

8. Te Molder MEM, Smolders JMH, Heesterbeek PJC, et al. Definitions of poor outcome after total knee arthroplasty: an inventory review. BMC Musculoskelet Disord. 2020;21:378. https://doi.org/10.1186/s12891-02003406-y.

9. Jette DU, Hunter SJ, Burkett L, et al. Physical therapist management of total knee arthroplasty. Phys Ther. 2020. https://doi.org/10.1093/ptj/pzaa099.

10. Lavernia CJ, Heiner AD, Cronin MH, et al. Prolonged conservative management in total joint arthroplasty: harming the patient? J Arthroplasty. 2017;32:S81-s85. https://doi.org/10.1016/j.arth.2017.03.034.

11. Gianola S, Stucovitz E, Castellini G, et al. Effects of early virtual reality-based rehabilitation in patients with total knee arthroplasty: a randomized controlled trial. Medicine (Baltimore). 2020;99:e19136. https://doi.org/10. 1097/md.0000000000019136.

12. Jogi P, Overend TJ, Spaulding SJ, et al. Effectiveness of balance exercises in the acute post-operative phase following total hip and knee arthroplasty: a randomized clinical trial. SAGE Open Med. 2015;3:2050312115570769. https://doi.org/10.1177/2050312115570769.

13. Nallegowda M, Singh U, Bhan S, et al. Balance and gait in total hip replacement: a pilot study. Am J Phys Med Rehabil. 2003;82:669-77. https://doi.org/10.1097/01.phm.0000083664.30871.c8.

14. Moher D, Liberati A, Tetzlaff J, et al. Preferred reporting items for systematic reviews and meta-analyses: the PRISMA statement. PLoS med. 2009;6: e1000097.

15. Bitterli R, Sieben JM, Hartmann M, et al. Pre-surgical sensorimotor training for patients undergoing total hip replacement: a randomised controlled trial. Int J Sports Med. 201 1;32:725-32. https://doi.org/10.1055/s-00311271696.

16. Gstoettner M, Raschner C, Dirnberger E, et al. Preoperative proprioceptive training in patients with total knee arthroplasty. Knee. 2011;18:265-70. https://doi.org/10.1016/j.knee.2010.05.012.

17. Huber EO, Roos EM, Meichtry A, et al. Effect of preoperative neuromuscular training (NEMEX-TJR) on functional outcome after total knee replacement: an assessor-blinded randomized controlled trial. BMC Musculoskelet Disord. 2015;16:101. https://doi.org/10.1186/s12891-015-0556-8.

18. Liao CD, Liou $T H$, Huang $Y Y$, et al. Effects of balance training on functional outcome after total knee replacement in patients with knee osteoarthritis: a randomized controlled trial. Clin Rehabil. 2013;27:697-709. https://doi.org/ 10.1177/0269215513476722.

19. Piva SR, Gil AB, Almeida GJ, et al. A balance exercise program appears to improve function for patients with total knee arthroplasty: a randomized clinical trial. Phys Ther. 2010;90:880-94. https://doi.org/10.2522/ptj.20090150.

20. Roig-Casasús S, Blasco JM, López-Bueno L, et al. Balance training with a dynamometric platform following total knee replacement: a randomized controlled trial. J Geriatr Phys Ther. 2018;41:204-9. https://doi.org/10.1519/ jpt.0000000000000121.

21. Villadsen A, Overgaard S, Holsgaard-Larsen A, et al. Postoperative effects of neuromuscular exercise prior to hip or knee arthroplasty: a randomised controlled trial. Ann Rheum Dis. 2014;73:1130-7. https://doi.org/10.1136/ annrheumdis-2012-203135.
22. Morri $M$, Vigna $D$, Raffa $D$, et al. Effect of game based balance exercises on rehabilitation after knee surgery: a controlled observational study. J Med Syst. 2019;43:141. https://doi.org/10.1007/s10916-019-1271-z.

23. Kakavas $G$, Malliaropoulos N. Neuroplasticity and anterior cruciate ligament injury. Indian J Orthop. 2020;54:275-80. https://doi.org/10.1007/ s43465-020-00045-2.

24. Nam D, Nunley RM, Barrack RL. Patient dissatisfaction following total knee replacement: a growing concern? Bone Joint J, 2014, 96-b: 96-100 DOl: 10 1302/0301-620x.96b11.34152.

25. Kosek E, Roos EM, Ageberg E, et al. Increased pain sensitivity but normal function of exercise induced analgesia in hip and knee osteoarthritis-treatment effects of neuromuscular exercise and total joint replacement. Osteoarthritis Cartilage. 2013;21:1299-307. https://doi.org/10.1016/j.joca. 2013.06.019.

26. Lee $\mathrm{SY}$, Jung SH, Lee SU, et al. Effect of balance training after hip fracture surgery: a systematic review and meta-analysis of randomized controlled studies. J Gerontol A Biol Sci Med Sci. 2019;74:1679-85. https://doi.org/10. 1093/gerona/gly271.

\section{Publisher's Note}

Springer Nature remains neutral with regard to jurisdictional claims in published maps and institutional affiliations.
Ready to submit your research? Choose BMC and benefit from:

- fast, convenient online submission

- thorough peer review by experienced researchers in your field

- rapid publication on acceptance

- support for research data, including large and complex data types

- gold Open Access which fosters wider collaboration and increased citations

- maximum visibility for your research: over $100 \mathrm{M}$ website views per year

At BMC, research is always in progress.

Learn more biomedcentral.com/submissions 